\title{
MODEL MANAJEMEN PELAKSANAAN SUPERVISI AKADEMIK PENGAWAS MADRASAH ALIYAH DI BARAT SELATAN ACEH
}

\author{
Hanifuddin Jamin \\ Sekolah Tinggi Agama Islam Negeri Teungku Dirundeng Meulaboh \\ hanifstainmbo@gmail.com
}

\begin{abstract}
ABSTRAK
Penelitian ini dilakukan di Madrasah Aliyah dan Pengawas Tingkat Aliyah di Barat Selatan Aceh bertujuan untuk mengetahui Bagaimana Manajemen Perencanaan Pelaksanaan Supervisi Akademik yang dilakukan oleh Pengawas Madrasah, Pendekatan yang digunakan dalam penelitian ini yaitu pendekatan kualitatif, teknik pengumpulan data melalui observasi, wawancara dan studi dokumentasi, subjek penelitian adalah Pengawas Madrasah, Kepala Madrasah dan guru. Penelitian ini memberikan kesimpulan bahwa, program supervisi Akademik yang disusun oleh pengawas madrasah adalah meliputi program semester dan program tahunan yang meliputi pembinaan kinerja guru dalam kelompok dan pembinaan individual guru. Pelaksanaan supervisi Akademik dalam rangka peningkatan kompetensi professional guru dilakukan melalui observasi kelas, pertemuan individu, diskusi kelompok dan demontrasi mengajar.
\end{abstract}

Kata Kunci: Manajemen, Supervisi Akademik, Pengawas, Madrasah

\begin{abstract}
ABSTRAC
This research was conducted at Madrasah Aliyah and Aliyah Level Supervisors in South West Aceh. The aim of this research was to find out how the Management of Academic Supervision Implementation Planning is carried out by Madrasah Supervisors. The approach used in this research is a qualitative approach, data collection techniques through observation, interviews and documentation studies, The research subjects were Madrasah Supervisors, Madrasah Principals and teachers. This study concludes that the academic supervision program prepared by the madrasa supervisor includes semester programs and annual programs which include teacher performance development in groups and individual teacher development. The implementation of academic supervision in order to increase the professional competence of teachers is carried out through class observations, individual meetings, group discussions and teaching demonstrations.
\end{abstract}

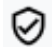

Keywords: Management, Academic Supervision, Supervisor Madrasah

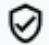




\section{PENDAHULUAN}

Supaya menghasilkan guru yang memiliki kompetensi maka perlu dilakukan pembinaan dan pengawasan secara terus-menerus sesuai dengan perkembangan. Kegiatan pembinaan terhadap tenaga kependidikan biasanya disebut supervisi atau pengawasan pendidikan. Boarman (Jamin, 2015) Mengemukakan bahwa Supervisi adalah:

Supervisi dapat diartikan sebagai usaha menstimulasi, mengkoordinasi, dan membimbing secara continue (terusmenerus) pertumbuhan guru-guru di Madrasah baik itu secara indifidual maupun secara kolektif, agar lebih mengerti dan lebih efektif dalam melibatkan seluruh fungsi pengajaran. Dengan demikian mereka dapat menstimulasi dan membimbing pertumbuhan setiap murid secara continue serta mampu dan lebih cakap berpartisipasi dalam masyarakat demokrasi dan modern.

Dalam kegiatan supervisi orang yang bertugas sebagai pengawas dalam melakukan pengawasan adalah pengawas Sekolah/Madrasah yang sering disebut sebagai supervisor. Pengawas bertugas memonitor, mengawasi dan membina kepala Sekolah/Madrasah, guru dan pegawai lainnya dalam upaya peningkatan mutu pendidikan di Sekolah/Madrasah. Dengan demikian, jelaslah bahwa keberadaan pengawas Sekolah/Madrasah adalah sebagai pengarah, penentu dan pembawa keberhasilan pelaksanaan pendidikan di Sekolah/Madrasah.

Dari uraian di atas dapat dipahami bahwa supervisi pengawas madrasah merupakan suatu keharusan yang harus dilaksanakan secara profesional. Fungsi pengawasan menjadi salah satu barometer keberhasilan pendidikan di Madrasah. Supervisi pengawas yang professional dan memiliki kompetensi sebaai pengawas sesuai dengan (Permen_12_Th-2007.Pdf, n.d.) Tentang Standar Pengawas Sekolah/Madrasah menegaskan bahwa seorang pengawasharus memiliki 6 kompetensi minimal, yaitu kompetensi kepribadian, supervisi manajerial, supervisi akademik, evaluasipendidikan, penelitian dan pengembangan, kompetensi kepribadianserta kompetensi social. proses pengawasan atau supervisi dalam pendidikan menempati posisi yang sangat strategis dan sekaligus menjadi perhatian di kalangan masyarakat dalam proses pengembangan pendidikan di Indonesia. Hal ini juga diperkuat dengan diberlakukannya (UU_1999_22.Pdf, n.d.) yang dikenal dengan Undang-Undang Otonomi Daerah yang diberi kebebasan untuk mengatur dan mengurus kepentingan 
aspirasi masyarakat sesuai dengan peraturan perundang undangan. Agar pengawasan dapat terlaksana dengan baik, maka harus didukung dengan proses manajemen yang baik atau pengawas secara rutin dan kontinyu dalam melaksanakan tugas dan tanggung jawabnya sebagai pengawas Sekolah/Madrasah dalam melaksanaka tugasnya Sujana, Nana (2011:5) Pengawas profesional adalah:

Pengawas Madrasah/Sekolah yang melakukan tugas pokok kepengawasan yang terdiri dari melaksanakan kegiatan pengawasan akademik dan pengawasan manajerial serta kegiatan pembimbingan dan pelatihan profesional guru dengan optimal yang didukung oleh standar dimensi kompetensi prasyarat yang dibutuhkan yang berkaitan dengan (1) pegawasan madrasah (2) pengembangan profesi (3) teknis operasional dan wawasan pendidikan.

Supervisi akademik diarahkan kepada meningkatkan aktifitas mengajar guru melalui kegiatan bimbingan, dorongan, arahan, dan bantuan dalam upaya meningkatkan dan perbaikan kualitas pembelajaran. Hal inilah yang secara terus menerus dilakukan oleh pengawas Madrasah di Barat selatan Aceh meliputi Kabupaten Aceh Jaya, Aceh Barat, Nagan Raya, Aceh Barat Daya dan Aceh Selatan. Dari studi pendahuluan yang dilakukan peneliti, di Madrasah Aliyah di lima kabupaten yang ada dibarat selatan aceh tentang manajemen pelaksanaan supervisi akademik berpengaruh pada peningkatan kualitas pendidikan pada lima kabupaten tersebut.

Dari uraian di atas dapat dipahami bahwa supervisi pengawas madrasah merupakan suatu keharusan yang harus dilaksanakan secara profesional. Fungsi pengawasan menjadi salah satu barometer keberhasilan pendidikan di Madrasah. Supervisi pengawas yang profesional sangat dinantikan oleh tenaga kependidikan, termasuk kepala madrasah, guru, peserta didik, dan juga seluruh orang tua peserta didik, masyarakat serta semua orang yang peduli terhadap upaya mencerdaskan kehidupan bangsa melalui pendidikan. proses pengawasan atau supervisi dalam pendidikan menempati posisi yang sangat strategis dan sekaligus menjadi perhatian di kalangan masyarakat dalam proses pengembangan pendidikan di Indonesia. Dengan demikian pelaksanaan, peran dan tugas pengawas dengan baik akan menampilkan supervisi pengawas yang profesional. Pengawasan pendidikan yang dilaksanakan oleh pengawas harus secara professional dalam melaksanakan tugasnya. Sujana, Nana (2011:5) Pengawas profesional adalah 
Pengawas Madrasah/Sekolah yang melakukan tugas pokok kepengawasan yang terdiri dari melaksanakan kegiatan pengawasan akademik dan pengawasan manajerial serta kegiatan pembimbingan dan pelatihan profesional guru dengan optimal yang didukung oleh standar dimensi kompetensi prasyarat yang dibutuhkan yang berkaitan dengan (1) pegawasan madrasah pengembangan profesi (3) teknis operasional dan wawasan pendidikan.

\section{METODE PENELITIAN}

Pendekatan penelitian yang digunakan dalam penelitian ini adalah menggunakan pendekatan kualitatif. Metode kualitatif yaitu penelitian yang berusaha mengumpulkan dan memahami data konkret, kemudian dilaporkan dalam bentuk uraian deskriptif, sehingga gambaran realita dapat dihadirkan. Hal tersebut sesuai dengan pendapat (Satori dan Komariah, 2010:25) bahwa penelitian kualitatif adalah suatu pendekatan penelitian yang mengungkap situasi sosial tertentu dengan mendeskripsikan situasi kenyataan secara benar, di bentuk oleh kata-kata berdasarkan teknik pengumpulan dan analisis data yang relevan yang diperoleh dari situasi yang alamiah. Subjek penelitian ini adalah Pengawas Madrasah, Kepala Madrasah dan Guru Tingkat Madrasah Aliyah di Kabupaten Aceh Jaya, Aceh Barat, Nagan Raya, Aceh Barat Daya dan Aceh Selatan. Lofland (Moleong) menyebutkan sumber data utama dalam penelitian kualitatif ialah kata-kata dan tindakan selebihnya adalah data tambahan seperti dokumen, sumber data tertulis, foto dan statistik Sedangkan tekhnik pengumupan datanya peneliti menggunakan Tekhnik Observasi, Wawancara dan dokumentasi (Tohirin 2012).

\section{HASIL DAN PEMBAHASAN}

\section{Manajemen perencanaan supervisi akademik}

Manajemen Pelaksanaan supervisi akademik yang baik sebaiknya direncanakan terlebih dahulu sebelum melakukan kunjungan ke sekolah/Madrasah sebagaimana hasil wawancara dengan C1 di Kabupaten Aceh Selatan:

Sebagai pengawas Madrasah saya selalu membuat program supervisi baik program tahunan maupun program semester. Supervisi Akademik yang berlangsung di Kementerian Agama dibagi kepada dua. Ada yang tidak direncanakan atau dilakukan secara tiba-tiba dan ada yang direncanakan. Supervisi yang direncanakan dilakukan dengan cara terlebih dahulu disiapkan kepala sekolah jadwal guru yang akan disupervisi, kemudian pengawas bersama kepala sekolah melaksanakan supervisi terhadap guru, sesuai dengan jadwal yang 
sudah ditentukan. Supervisi yang direncanakan bertujuan untuk membantu guru mengembangkan kemampuan mengelola proses pembelajaran, sehingga tercapai tujuan pembelajaran. Perencanaan supervisi pada awalnya dilakukan di kantor Kementerian Agama dengan seluruh kelompok kerja pengawas (Pokjawas), kemudian hasil musyawarah itulah yang akan disampaikan kepada setiap sekolah dan sekolah kembali memusyawarhkan hari pelaksanaan supervisi. Program supervisi yang telah direncanakan biasanya dilaksanakan pada awal semester. Tujuannya adalah agar tersosialisasi dengan baik program pengawasan sebagaimana yang diinginkan.

Program Tahunan Pengawas Madrasah

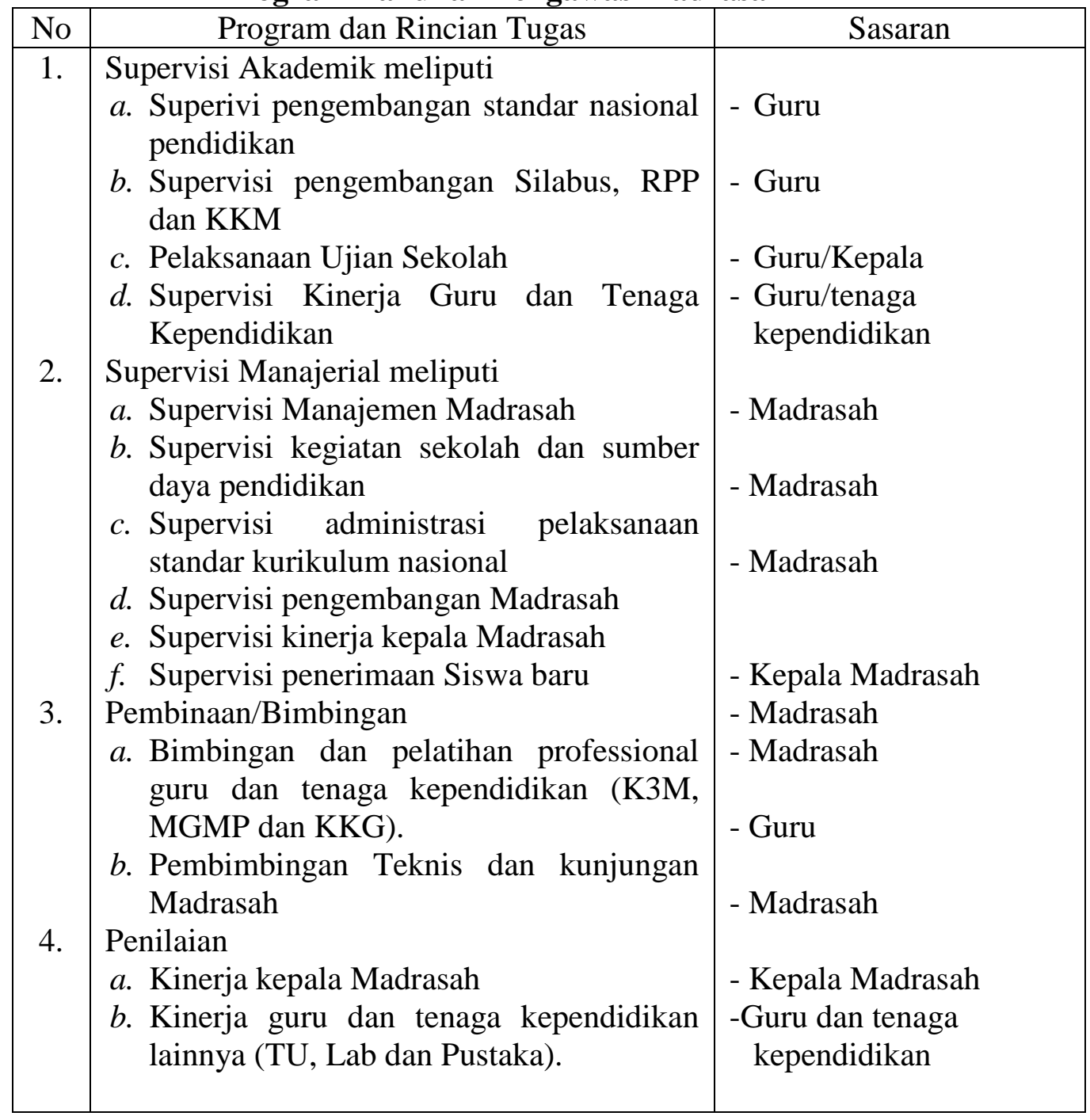

Program Semester Pengawas Madrasah

\begin{tabular}{c|l|l}
\hline No & \multicolumn{1}{|c|}{ Tujuan } & \multicolumn{1}{|c}{ Sasaran } \\
\hline 1. & $\begin{array}{l}\text { Tujuan Rencana Kepengawasan Manajerial } \\
\text { meliputi }\end{array}$ & $\begin{array}{l}\text { - Kepala, Guru } \\
\text { - Tenaga Kependidikan }\end{array}$ \\
\hline
\end{tabular}




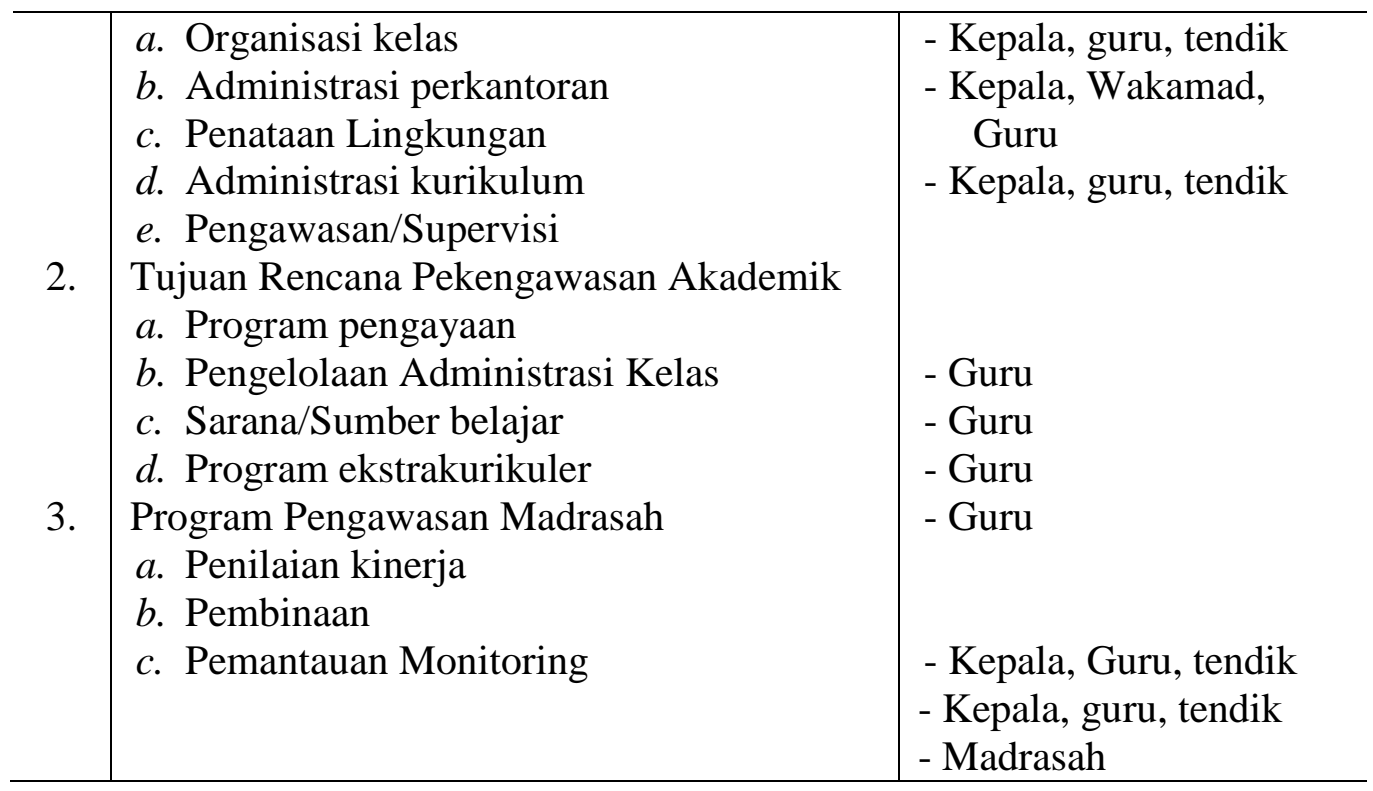

Berdasarkan informasi di atas, dapat dipahami setiap pengawas sebelum melakukan supervisi terlebih dahulu membuat Program Tahunan dan Program Semester Pelaksanaan Supervisi Akademik Sasaran utama supervisi akademik adalah kemampuan-kemampuan guru dalam merencanakan kegiatan pembelajaran, melaksanakan kegiatan pembelajaran, menilai hasil pembelajaran, memanfaatkan hasil penilaian untuk peningkatan layanan pembelajaran, menciptakan lingkungan belajar yang menyenangkan, memanfaatkan sumber belajar yang tersedia, dan mengembangkan interaksi pembelajaran (strategi, metode, teknik) yang tepat. Hal ini erat kaitannya dengan informasi yang disampaikan oleh C2 dikabupaten Aceh Jaya sebagai berikut :

Saya sebagai seorang supervisor melakukan supervisi yang meliputi beberapa aspek, yaitu perencanaan pembelajaran, apakah ada direncanakan atau tidak oleh guru-guru di Madrasah tersebut. Kemudian, supervisi yang berhubungan dengan administrasi guru yang meliputi program semester, silabus, RPP, jadwal tatap muka, agenda harian, daftar nilai, dan absensi siswa. Pada komponen pelaksanaan pembelajaran, kegiatan supervisi diarahkan pada kemampuan guru dalam mengelola kelas, dimulai dari kegiatan pendahuluan, kegiatan inti, dan penutup. Sedangkan pada kegiatan tindak lanjut, kegiatan supervisi diarahkan pada pembimbingan dan pelatihan profesional guru, dan dilakukan upaya perbaikan mutu pendidikan melalui supervisi administrasi penilaian pembelajaran dengan jalan pembimbingan guru-guru sebagai refleksi dan feedback hasil penilaian supervisi yang telah dilaksanakan.

Selanjutnya, peneliti juga menanyakan kepada pengawas tentang rencana pelaksanaan supervisi. Dari wawancara yang berlangsung, diperoleh informasi bahwa 
supervisi Akademik dilaksanakan dengan terlebih dahulu bermusyawarah dengan pihak Madrasah. Hal tersebut senada dengan yang diungkapkan oleh C2 di Aceh Jaya menjelaskan:

Dalam pelaksanaan supervisi, saya terlebih dahulu mengawalinya dengan melakukan pertemuan awal dengan kepala madrasah dan guru-guru serta staf administrasi madrasah, sebab dengan pertemuan itu saya dengan kepala madrasah, guru-guru dan staf administrasi melakukan kata sepakat untuk bekerja sama melaksanakan supervisi. Selain itu disetiap madrasah ada kepala madrasah yang menjadi pimpinan disitu, saya harus minta izin terlebih dahulu kepadanya, baru saya laksanakan tugas saya sebagai pengawas. Diawal pertemuan itulah dijadwalkan rencana-rencana pelaksanaan supervisi di sekolah tersebut, sehingga dapat dipahami secara bersama-sama.

Berdasarkan informasi yang diperoleh dari kepala Madrasah dan juga informasi dari supervisor, dapat dipahami bahwa hakikat pelaksanaan supervisi Akademik adalah untuk memberikan bimbingan dan arahan bagi guru di Madrasah, termasuk dalam hal ini adalah personalia madrasah lainnya yang langsung menangani belajar peserta didik.

Dari beberapa paparan di atas dapat disimpulkan bahwa (1) Setiap pengawas Madrasah merencanakan program supervisi terlebih dahulu sebelum melakukan kunjungan supervisi ke Madrasah (2) salah satu usaha untuk meningkatkan kualitas pembelajaran Guru adalah dengan melakukan supervisi bagi guru; (3) guru membutuhkan bimbingan dari seorang supervisor atau pengawas; (4) dalam melaksanakan tugas pengawasan, pengawas melakukan supervisi sesuai dengan jadwal yang telah direncanakan; (5) perencanaan supervisi akademik dilakukan pada awal semester dengan terlebih dahulu melakukan musyawarah dengan melibatkan beberapa komponen, seperti pengawas Madrasah, kepala madrasah dan guru; (6) perencanaan supervisi Akademik pada prinsipnya dilakukan dalam mendukung lancarnya tugas pengawasan, sehingga jelas apa yang dikerjakan, bagaimana mengerjakannya, dan siapa yang mengerjakannya; (7) rencana supervisi akademik yang telah dimusyawarahkan secara bersama-sama, kemudian disusun dalam program supervisi; (8) program disusun sebagai acuan untuk melaksanakan supervisi; (9) penyusunan program yang dimaksud adalah pembuatan jadwal kunjungan dan pembuatan penyiapan instrumen penilaian. 


\section{Pelaksanaan supervisi akademik oleh pengawas}

Supervisi akademik merupakan tanggung jawab bersama antara supervisor, kepala dan guru. Dalam kaitan ini, maka pelaksanaan supervisi pengawas Madrasah dengan kepala madrasah pada kegiatan belajar di Madrasah Aliyah di Barat selatan Aceh mencakup tiga tahapan, yaitu tahap persiapan, tahap pelaksanaan dan tahap penilaian dan tindak lanjut. Hal ini diketahui dari hasi wawancara dengan C3 sebagai berikut:

Untuk mencapai kelancaran supervisi Akademik di Madasah kita pihak Madrasah, terutama kepala sekolah dengan pengawas melakukan kerjasama. Kita membicarakan bersama-sama solusi yang paling tepat untuk dilakukan dalam meningkatkan kualitas guru. Kemudian kita melakukan pengamatan, mempersiapkan segala sesuatu yang berkaitan dengan perangkat pembelajaran, kita siapkan instrumen penilaiannya dan kemudian kita melakukan kunjungan kelas. Setalah melakukan kunjungan kelas, kemudian diadakan refleksi, dan pembinaan terhadap guru-guru di Madrasah.

Penjelasan yang hampir sama juga diperoleh penulis dari hasil wawancara penulis dengan C4 di Kabupaten Aceh Selatan.

Dalam pelaksanaan supervisi Akademik, kita melakukan sharing dengan guru yang bersangkutan. Kita melakukan persiapan-persiapan yang terkait dengan pelaksanaan supervisi. Setelah itu, kita langsung melakukan kunjungan supervisi ke kelas. Hasil dari supervisi itu, kemudian kita jadikan bahan diskusi dengan kepala sekolah, apakah ada yang harus diperbaiki atau tidak.

Dari uraian di atas, dapat dipahami bahwa dalam tahap pelaksanaan supervisi, supervisor melaksanakan tiga tahapan, yaitu persiapan pelaksanaan supervisi, pelaksanaan supervisi dan evaluasi supervisi. Ketiga macam proses atau langkah-langkah supervisi tersebut diaplikasikan oleh pengawas Madrasah. Hal ini menunjukkan bahwa telah direncanakan dengan bagus oleh pengawas madrasah dalam pelaksanaan supervisi.

Pada tahap pelaksanaan supervisi, pengawas melakukan supervisi dengan cara kunjungan kelas. Sebagaimana telah dijelaskan di atas, bahwa supervisi disesuaikan dengan jadwal mengajar guru yang akan disupervisi, maka dalam melakukan kunjungan supervisi, pengawas tidak lagi memberitahukan akan dilaksanakan supervisi. Informasi supervisi hanya disampaikan kepada kepala madrasah. Dalam pelaksanaan ini, ada dua cara yang dilakukan pengawas, yaitu secara langsung bertemu 
dengan guru yang bersangkutan dan kadang-kadang hanya dilakukan tanpa bertemu langsung dengan guru yang bersangkutan. Sebagaimana dijelaskan C5 pada saat diwawancarai:

Dalam melaksanakan supervisi Akademik, kita tidak lagi memberitahukan kepada guru bersangkutan, sebab kita sudah menyepakati secara bersama-sama, bahwa supervisi dilakukan pada saat guru bersangkutan mengajar. Ini dilakukan, supaya guru yang bersangkutan mempersiapkan seluruh perangkat yang akan disupervisi dan di bawanya langsung pada saat mengajar. Jadi lebih praktis. Kadang-kadang, kita tidak bertemu dengan guru yang akan disupervisi. Kita hanya meminta kepada guru bersangkutan untuk mengumpulkan perangkat yang terkait dengan bahan- bahan yang akan disupervisi, dan menyerahkannya kepada kepala sekolah. Kemudian kepala sekolah memberikan kepada pengawas untuk diperiksa atau dinilai.

Sedangkan dilihat dari teknik, pelaksanaan pengawas menerapkan atau melaksanakan kegiatan supervisi dengan teknik-teknik yang cukup bervariasi. Dari data yang dijelaskan di atas, dapat dipahami bahwa teknik- teknik kegiatan supervisi pengawas Madrasah dilakukan dengan dua cara, yaitu teknik individual dan dan teknik kelompok.

Teknik supervisi individual adalah pelaksanaan supervisi yang diberikan kepada guru tertentu yang mempunyai masalah khusus dan bersifat perorangan. Supervisor atau pengawas berhadapan dengan seorang guru yang dipandang memiliki persoalan tertentu. Teknik-teknik supervisi yang dikelompokkan sebagai teknik individual meliputi: kunjungan kelas, observasi kelas, pertemuan individual, kunjungan antar kelas, dan menilai diri sendiri.

\section{KESIMPULAN}

Setiap pengawas Madrasah dalam penyusunan perencanaan pelaksanaan supervisi akademik disusun secara bersama-sama dengan Pojawas untuk merencanan Program Tahunan dan Program Semester pelaksanaan Supervisi Akademik untuk satu tahun kedepan dengan beban kerja pengawas Madrasah yang tetap ditentukan dengan beban kerja perminggu 37,5 Jam

Teknik- teknik Pelaksanaan kegiatan supervisi pengawas Madrasah dilakukan dengan dua cara, yaitu teknik individual dan dan teknik kelompok. Teknik supervisi individual adalah pelaksanaan supervisi yang diberikan kepada guru tertentu yang mempunyai masalah khusus dan bersifat perorangan. Supervisor atau pengawas 
berhadapan dengan seorang guru yang dipandang memiliki persoalan tertentu. Teknikteknik supervisi yang dikelompokkan sebagai teknik individual meliputi: kunjungan kelas, observasi kelas, pertemuan individual, kunjungan antar kelas, dan menilai diri sendiri.

DAFTAR PUSTAKA

Moleong, J Lexy. “Metodologi Penelitian Kualitatif”.Bandung: PT. Remaja Rosda Karya 2014). Hal.157 
Iskandar, A. (2020). MANAJEMEN SUPERVISI AKADEMIK KEPALA

MADRASAH . Jurnal Isema : Islamic Educational Management, 5(1), 69-

82. https://doi.org/10.15575/isema.v5i1.5976

Permen_12_Th-2007.pdf. (n.d.).

Permenag Nomor 2 Tahun 2012.pdf. (n.d.).

Tohirin "Metode Penelitian Kualitatif dalam Pendidikan dan Bimbingan Konseling", (Jakarta: PT. Raja Grafindo Persada, 2012).hal 68

UU_1999_22.pdf.(n.d.).

Sagala, S. (2009). Kemampuan Profesional Guru dan Tenaga Kependidikan: Pemberdayaan guru, tenaga kependidikan, dan masyarakat dalam manajemen sekolah. Bandung. Alfabeta.

Sujana, Nana, "Buku Kerja Pengawas", Jakarta: Pusat Pengembangan Tenaga Kependidikan, Badan PSDM dan PMP Kementerian Pendidikan Nasional 2012

Satori, Djam'an dan Komariah, Aan, “Metodologi Penelitian Kualitatif”, (Bandung: Alfabeta. 2010). 